\title{
A prospective comparative study of oral and vaginal misoprostol after pre-treatment with single dose of mifepristone for second trimester abortion
}

\author{
Aastha Bhaskar ${ }^{1 *}$, Richa Kaushik ${ }^{1}$, Ashwani Kumar ${ }^{2}$
}

\begin{abstract}
${ }^{1}$ Department of Obstetrics and Gynecology, ${ }^{2}$ Department of Neurosurgery, Pt. B. D. Sharma P.G.I.M.S., Rohtak, Haryana, India
\end{abstract}

Received: 24 October 2017

Accepted: 17 November 2017

\author{
*Correspondence: \\ Dr. Aastha Bhaskar, \\ E-mail: richa.koushik@gmail.com
}

Copyright: (c) the author(s), publisher and licensee Medip Academy. This is an open-access article distributed under the terms of the Creative Commons Attribution Non-Commercial License, which permits unrestricted non-commercial use, distribution, and reproduction in any medium, provided the original work is properly cited.

\begin{abstract}
Background: Misoprostol is a synthetic PGE1 analogue which induces cervical ripening as well as strong uterine contractions and leads to expulsion of pregnancy. Misoprostol has been shown to have several advantages over other prostaglandins; it is cheap, stable at room temperature and can be given by various routes. Administration of mifepristone 24 to 48 hours before misoprostol decreases mean induction time which varies with route of administration of misoprostol.

Methods: 50 women with single intrauterine pregnancy with gestational age 13-20 weeks, admitted in labour room of Obstetrics and Gynaecology, Pt. B.D. Sharma PGIMS, Rohtak for termination of pregnancy (on account of missed abortion, absent liquor or gross congenital malformation) were given $200 \mathrm{mg}$ of mifepristone orally after taking written informed consent and excluding scarred uterus, placenta praevia, bronchial asthma, any cardiovascular disease, clotting disorder, long term use of glucocorticoids and history of glaucoma. Then they were randomized into two groups of 25 women each. Group I included 25 women who received oral misoprostol and group II included 25 women who received vaginal misoprostol. Complete abortion was defined as successful expulsion of both foetus and placenta without any intervention. Failure was defined as cases with incomplete expulsion or incomplete dilatation or no dilatation.
\end{abstract}

Results: The mean number of doses of misoprostol used in groups I and group II were $2.80 \pm 1.19$ and $2.20 \pm 0.86$ respectively and the difference was statistically significant (p value 0.04). Out of 25 patients included in each group, $64 \%(n=16)$ in group I and $80 \%(n=20)$ in group II patients had complete expulsion with misoprostol and remaining $36 \%(n=9)$ in group I and $20 \%(n=5)$ in group II either needed syntocinon or post expulsion evacuation for retained product of conceptions and who did not respond to the given doses of misoprostol at all required mechanical dilatation and evacuation. But this difference was not statistically significant. The mean induction abortion interval in cases of complete expulsion observed in group I was $10.74 \pm 4.12$ hours and $8.67 \pm 3.23$ hours in group II which was statistically significant ( $\mathrm{p}$ value 0.05 ).

Conclusions: Vaginal route is better than oral route for second trimester termination of pregnancy as it requires less number of Misoprostol doses and shorter induction abortion interval.

Keywords: Abortion, Mifepristone, Misoprostol, Oral, Vaginal 


\section{INTRODUCTION}

The National Centre for Health Statistics defines an "abortus" as "foetus or embryo removed or expelled from the uterus during the first half of gestation - 20 weeks or less, or in the absence of accurate dating criteria, born weighing < 500 g."1 An abortion can occur spontaneously, in which it is called a miscarriage, or it can be purposely induced. Estimates indicate that 46 million pregnancies are voluntarily terminated each year, 27 million legally and 19 million outside the legal system. $^{2}$ Although the majority of abortions are performed in the first trimester, there is still a need for second trimester abortion because of delayed diagnosis of foetal anomalies, logistic and financial difficulties in obtaining abortion services, and failure to recognise an undesired pregnancy in the first trimester, which all contribute to the continuing need for late abortions. ${ }^{3,4}$

While abortion is one of the safest medical procedures, the risk to women undergoing abortion increases with gestation. The cost of abortion can vary dramatically and increases exponentially, the longer the pregnancy continues.

Different surgical and medical methods of abortion have been used since ancient times. Surgical abortion is one of the oldest and most commonly practised techniques in many parts of the world. Medical abortion refers to an abortion induced by pharmaceutical agents. It has evolved as a popular option for women wishing pregnancy termination. A matter of great concern in the past was that there were no safe drugs for inducing an abortion. Women have used various herbs, salts, douches and purgatives; all with questionable success to achieve pregnancy termination. ${ }^{5}$ With the introduction of prostaglandins and later prostaglandin analogues, the efficacy of medical abortion could be improved, and the risk of complications and side effects reduced. The efficacy of medical induced abortion further improved when mifepristone became available in the 1980s. ${ }^{6-10}$ With mifepristone, the induction-to-abortion interval was shortened, and the less dose of prostaglandin analogues was required thus side effects was reduced. Today, medical abortion is the method of choice in many centres. ${ }^{11}$

Mifepristone is the only antiprogestin approved for the induction of abortion. It is a 19- non-steroid, which binds with high affinity to the progesterone receptor, thus inhibiting the effect of progesterone resulting in vascular damage, decidual necrosis and bleeding, which leads to cervical softening, increased uterine sensitivity to PG and conversion of the quiet pregnant uterus into an organ of spontaneous activity with maximal effect at 36-48 hours. ${ }^{9-24}$

PGs play an important role in the regulation of uterine contractility during pregnancy. ${ }^{25}$ The receptors are present throughout the pregnancy; hence, PGs and PG analogues are effective for termination of pregnancy. Misoprostol is a synthetic $\mathrm{PGE}_{1}$ analogue which induces cervical ripening as well as strong uterine contractions and leads to expulsion of a pregnancy. Misoprostol has been shown to have several advantages over other prostaglandins; it is cheap, stable at room temperature and can be stored for a long time. It can be given by various routes; rectal, vaginal, oral, sublingual etc. Administration of mifepristone 24 to 48 hours before misoprostol decreases mean induction time by up to $45 \%$, and it has been suggested that use of adjunctive mifepristone could make induction procedure more short. ${ }^{26}$

It is important to identify the best available regimen for use. Given the unclear picture regarding the efficacy of various regimens, this study was planned to compare the effectiveness, side-effects and outcome of oral and vaginal routes of misoprostol in second trimester abortion.

\section{METHODS}

This prospective randomised study was conducted on 50 women with single intrauterine pregnancy with gestational age 13-20 weeks, admitted in labour room of Obstetrics and Gynaecology, Pt. B.D. Sharma PGIMS, Rohtak for termination of pregnancy (on account of missed abortion, absent liquor or gross congenital malformation). Women with known scarred uterus, placenta praevia, bronchial asthma, any cardiovascular disease, clotting disorder, long term use of glucocorticoids and history of glaucoma were excluded from the study. All women were admitted after taking an informed written and witnessed by two doctors. Detailed history, general physical and obstetric examination was done in each woman. Following investigations were done at the time of admission - Haemoglobin ( $\mathrm{Hb})$, bleeding time (BT), clotting time (CT), blood group, HIV, HBsAg, VDRL and fasting blood sugar (FBS). Coagulation profile was done in case of missed abortion. Total leucocyte count, differential leucocyte count and high vaginal swab were done in case of absent liquor. A sonography was performed in all the women to confirm gestational age and exact placental localisation to confirm Gross congenital malformations (GCMF).

All women received tablet mifepristone at the time of enrolment. Misoprostol was given 36-48 hours the administration of mifepristone. All the enrolled women systematically randomised into two groups. Group I included 25 women who received oral misoprostol and group II included 25 women who received vaginal misoprostol.

Women of group I received 400 microgram of oral misoprostol every 4 hours for a maximum of 7 doses while women of group II received 400 microgram of vaginal misoprostol every 4 hours for a maximum of 7 doses. Before administering next dose of misoprostol, 
patient was assessed for uterine contraction and cervical dilatation. Once woman had good uterine contractions, next dose omitted.

Complete abortion was defined as the expulsion of both foetus and placenta without operative intervention. Failure was defined as cases with incomplete expulsion or incomplete dilatation or no dilatation.

The primary outcome measures were induction abortion interval (which was defined as time from placement of the first dose of misoprostol until delivery of abortus) and total number of misoprostol doses that were required for induction.

The secondary outcome measures included length of hospital stay, side effects of medication and failure with regimen.

\section{Statistical analysis}

At the end of the study, data analysis was done by using Student t-test and Chi-square test. A p value of $<0.05$ was considered as significant.

\section{RESULTS}

Parity distribution of amongst two groups was statistically comparable. Mean parity in group I was $1.61 \pm 1.03$ and in group II was $1 \pm 0.79$ (Table 1 ).

Table 1: Parity distribution.

\begin{tabular}{|lll|}
\hline Parity & Group I & Group II \\
\hline P0 & N $(\%)$ & N $(\%)$ \\
\hline P1 & $9(36 \%)$ & $13(52 \%)$ \\
\hline P2 or more & $7(28 \%)$ & $7(28 \%)$ \\
\hline Mean parity* (mean \pm SD) & $1.61 \pm 1.03$ & $1 \pm 0.79$ \\
\hline *p value $>0.05$ (Statistically non-significant)
\end{tabular}

Mean period of gestation by patient's last menstrual date was $17.18 \pm 2.61$ in group I and $16.96 \pm 2.57$ in group II and was not statistically significant amongst groups. Mean period of gestation by ultrasonography as per BPD measurement was $15.04 \pm 2.05$ in group I and $15.28 \pm 2.47$ in group II which was found to be comparable and clinically not significant (Table 2 ).

Table 2: Period of gestation comparison.

\begin{tabular}{|lll|}
$\begin{array}{l}\text { Period of gestation } \\
\text { (weeks) (mean } \pm \text { SD) }\end{array}$ & Group I & Group II \\
\hline According to LMP* & $17.18 \pm 2.61$ & $16.96 \pm 2.57$ \\
\hline According to USG* & $15.28 \pm 2.47$ & $15.04 \pm 2.05$ \\
\hline *p value $=>0.05 *$ (Non-significant) & \\
\hline
\end{tabular}

Intrauterine death (IUD) was the commonest indication in both the groups i.e. $48 \%$ in group I and $56 \%$ in group II. Gross congenital malformations (GCMF) were present in
$44 \%$ cases in group I and $36 \%$ cases in group II. On comparison, no statistically significant difference was found in indication of termination of pregnancy in both the groups (Table 3 ).

Table 3: Indication of termination of pregnancy.

\begin{tabular}{|lll|}
\hline Indications & Group I & Group II \\
\hline IUD* & N $(\%)$ & N $(\%)$ \\
\hline PROM*t & $12(48 \%)$ & $14(56 \%)$ \\
\hline GCMF $^{*}$ & $2(8 \%)$ & $2(8 \%)$ \\
\hline
\end{tabular}

$* \mathrm{p}$ value $=>0.05 *($ Non-significant $)$

${ }^{\mathrm{f}}$ Premature rupture of membranes

In group I, mean doses of misoprostol used were

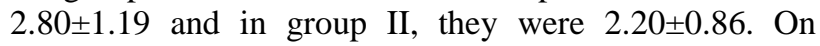
statistical comparison significantly, higher number of doses of Misoprostol was used in group II as compared to group II (p value 0.04) (Table 4).

Table 4: Number of doses of misoprostol.

\begin{tabular}{|lll|}
\hline $\begin{array}{l}\text { No. of misoprostol } \\
\text { doses }\end{array}$ & $\begin{array}{l}\text { Group I } \\
\text { N }(\%)\end{array}$ & $\begin{array}{l}\text { Group II } \\
\text { ( }(\%)\end{array}$ \\
\hline 1 & $2(8 \%)$ & $5(20 \%)$ \\
\hline 2 & $8(32 \%)$ & $12(48 \%)$ \\
\hline 3 & $11(44 \%)$ & $6(24 \%)$ \\
\hline 4 & $3(12 \%)$ & $2(8 \%)$ \\
\hline 4 & $1(4 \%)$ & 0 \\
\hline Mean \pm SD* & $2.80 \pm 1.19$ & $2.20 \pm 0.86$ \\
\hline
\end{tabular}

*p value 0.04 (Statistically significant)

When treatment outcome was compared $64 \%$ patients in group I and $80 \%$ patients in group II had complete expulsion with misoprostol. $16 \%$ patients in group I and $12 \%$ patients in group II had cervical dilatation without any expulsion. $16 \%$ patients in group I and $8 \%$ patients in group II had incomplete expulsion. $4 \%$ patients in group I had no cervical dilatation.

Failure cases needed syntocinon or post expulsion evacuation for retained product of conceptions and who did not respond to the given doses of misoprostol at all required mechanical dilatation and evacuation. No significant difference was found in both the groups (Table 5).

Table 5: Treatment outcome.

\begin{tabular}{|c|c|c|c|}
\hline \multicolumn{2}{|c|}{ Treatment outcome } & $\begin{array}{l}\text { Group I } \\
\text { N }(\%)\end{array}$ & $\begin{array}{l}\text { Group II } \\
\mathbf{N}(\%)\end{array}$ \\
\hline \multicolumn{2}{|c|}{ Complete expulsion* } & $16(64 \%)$ & $20(80 \%)$ \\
\hline \multirow{3}{*}{ Failure } & $\begin{array}{l}\text { Incomplete } \\
\text { expulsion* }\end{array}$ & $4(16 \%)$ & $2(8 \%)$ \\
\hline & $\begin{array}{l}\text { Cervical dilatation } \\
\text { present* }\end{array}$ & $4(16 \%)$ & $3(12 \%)$ \\
\hline & $\begin{array}{l}\text { Cervical dilatation } \\
\text { absent* }\end{array}$ & $1(4 \%)$ & 0 \\
\hline
\end{tabular}


The mean induction abortion interval in cases of complete expulsion of abortus observed in group I was $10.74 \pm 4.12$ hours and 8.67 \pm 3.23 hours in group II which was statistically significant (p value 0.05 ) (Table 6).

Table 6: Induction abortion interval in cases of complete expulsion.

\begin{tabular}{|lll|}
\hline Time, (hours) & Group I, (N-16) & Group II, (N-20) \\
\hline Mean \pm SD* & $10.74 \pm 4.12$ & $8.67 \pm 3.23$ \\
\hline *p value 0.05 (Statistically significant)
\end{tabular}

Total hospital stays of patients in both the groups showed that group I patients stayed in hospital slightly more as compared to group II patients. Mean hospital stay in group I cases was $4.28 \pm 0.54$ and in group II, it was 4.20 \pm 0.40 . Statistical analysis showed no significant difference and thus both the groups were found to be comparable (Table 7).

Table 7: Length of hospital stay.

\begin{tabular}{|c|c|c|}
\hline $\begin{array}{l}\text { Hospital stay } \\
\text { (days) }\end{array}$ & $\begin{array}{l}\text { Group I } \\
\mathbf{N}(\%)\end{array}$ & $\begin{array}{l}\text { Group II } \\
\mathbf{N}(\%)\end{array}$ \\
\hline 4 & $19(76 \%)$ & $20(80 \%)$ \\
\hline 5 & $5(20 \%)$ & $5(20 \%)$ \\
\hline 6 & $1(4 \%)$ & 0 \\
\hline Mean \pm SD* & $4.28 \pm 0.54$ & $4.20 \pm 0.40$ \\
\hline
\end{tabular}

\section{DISCUSSION}

Conventionally, termination of pregnancy has been carried out by surgical method. However, given the surgical hazards (such as uterine perforation, uterine rupture and haemorrhage) of the procedure, the search for alternative methods continued and lead to the discovery and use of pharmaceutical agents with abortifacient properties. $^{27}$

Mifepristone, a synthetic antiprogestin compound, was discovered in 1980s as glucocorticoid antagonist and it was found to possess high affinity not only for the glucocorticoid receptors, but also for the progesterone receptor. ${ }^{27}$ The ability of mifepristone to block the action of progesterone on gravid uterus has led to the development of its use as an abortifacient agent. Since its discovery, mifepristone has been used commonly for this purpose. Mifepristone and Misoprostol combination results in $95-100 \%$ abortion rate. ${ }^{28,29}$ The adverse effects observed after use of mifepristone are mainly gastrointestinal, including nausea, vomiting, abdominal pain and skin rashes. ${ }^{30}$ Introduction of Misoprostol in late 70's revolutionised the management of termination of pregnancy. It is known that prostaglandins stimulate uterine contractility at any stage of pregnancy and also cause cervical ripening and dilatation. ${ }^{31}$ Various studies have been reported regarding the efficacy of Misoprostol alone regimen for early medical termination of pregnancy and this regimen has found to be $93-95 \%$ efficacious. ${ }^{32,33}$
The most common adverse effects of Misoprostol are nausea, vomiting, abdominal pain, chills and fever, all of which are dose dependent. ${ }^{34}$

The present study, which was designed to compare the oral and vaginal routes of administration of Misoprostol for second trimester termination of pregnancy after pretreatment with single dose of mifepristone, concluded that vaginal route is better than oral route for second trimester termination of pregnancy as it requires less no of Misoprostol doses and shorter induction-abortion interval.

\section{Funding: No funding sources \\ Conflict of interest: None declared \\ Ethical approval: The study was approved by the Institutional Ethics Committee}

\section{REFERENCES}

1. Cunningham FG, Leveno KJ, Bloom SL, Sponge CY, Dash JS, Casey BM et al. Abortion. In: Textbook of Williams Obstetrics, $24^{\text {th }}$ ed. New York, McGraw Hill Co.;2005:350-76.

2. World Health Organization. Unsafe abortion global and regional estimates of the incidence of unsafe abortion and association mortality in $2000.4^{\text {th }} \mathrm{ed}$. 2004:82.

3. Drey EA, Foster DG, Jackson RA, Lee SJ, Cardenas LH, Darney PD. Risk factors associated with presenting for abortion in the second trimester. Obstetrics Gynecol 2006;107:128-35.

4. Grimes DA. The continuing need for late abortions. JAMA. 1998;280:747-50.

5. Bujalkova M. Birth control in antiquity. Bratisl Lek Listy. 2007;108:163-6.

6. Urquhart DR, Empleton AA. Mifepristone (RU 486) and second-trimester termination. Lancet 1987;2:1405.

7. Silvestre L, Dubois C, Renault M. Voluntary interruption of pregnancy with mifepristone (RU 486) and a prostaglandin analogue. A large-scale French experience. N Eng J Med. 1990;322:645-8.

8. Gottlieb C, Bygdeman M. The use of antiprogestin (RU 486) for termination of second trimester pregnancy. Acta Obstetrica et Gynecologica Scandinavica. 1991;70:199-203.

9. Bygdeman M, Swahn ML. Progesterone receptor blockage. Effect on uterine contractility and early pregnancy. Contraception. 1985;32:45-51.

10. Swahn ML, Bygdeman M. The effect of the antiprogestin RU 486 on uterine contractility and sensitivity to prostaglandin and oxytocin. Br J Obstet Gynecol. 1988;95:126-34.

11. Royal College of Obstetricians and Gynaecologists. Induced Abortion Guidelines No. 11. London7 RCOG, 1997.

12. Bartlett LA, Berg CJ, Shulman HB. Risk factors for legal induced abortion-related mortality in the United States. Obstet Gynecol. 2004;103:729-37. 
13. Elam-Evans LD, Strauss LT, Herndon J. Abortion surveillance - United States, 2000. Morbidity and Mortality Weekly Report Surveillance Summaries 2003;52:1-32.

14. Boyd PA, Tondi F, Hicks NR. Autopsy after termination of pregnancy for fetal anomaly: retrospective cohort study. BMJ. 2004;328:137.

15. Safe Abortion: Technical and Policy Guidelines for Health Systems. Geneva 7 World Health Organization, 2003.

16. Royal College of Obstetricians and Gynaecologists. The Care of Women Requesting Induced Abortion. Guidelines No.7. London, 2004.

17. Grimes DA, Schulz KF, Cates W Jr. Mid-trimester abortion by dilatation and evacuation: a safe and practical alternative. N Eng J Med. 1977;296:1141-5.

18. Autry AM, Hayes EC, Jacobson GF. A comparison of medical induction and dilation and evacuation for second trimester abortion. Am J Obstet Gynecol. 2002; 187:393-7.

19. Report of Confidential Enquires into Maternal Deaths in the United Kingdom (1994-1996) Why Mothers Die. Department of Health. London: Her Majesty's Stationary Office. 1997.

20. Lalitkumar S, Bygdeman M, Gemzell DK. Midtrimester induced abortion: a review. Hum Reprod Update. 2007;13:37-52.

21. World Health Organization. Unsafe Abortion: Global Estimates of the Incidence of Unsafe Abortion and Associated Mortality in 2000. $4^{\text {th }}$ ed. Geneva7 WHO, 2004.

22. Johannisson E, Oberholzer M, Swahn ML. Vascular changes in the human endometrium following the administration of the progesterone antagonist RU 486. Contraception. 1989;39:103-7.

23. Norman JE, Thong KJ, Baird DT. Uterine contractility and induction of abortion in early pregnancy by misoprostol and mifepristone. Lancet. 1991;338:1233-6.

24. Radestad A, Christensen NJ, Stromberg L. Induced cervical ripening with Mifepristone in first trimester abortion. A double blind randomized biomechanical study. Contraception. 1988;38:301-12.
25. Mitchell MD. Regulation of eicasanoid biosynthesis during pregnancy and parturition. In: Hiller K, editor. Eicsanoids and Reproduction. Lancaster 7 MTP Press, 1987:108-27.

26. Ngoc NT, Shochet T, Raghavan S. Mifepristone and misoprostol compared with misoprostol alone for second-trimester abortion: a randomized controlled trial. Obstet Gynecol. 2011;118:601-8.

27. Ulmann A, Teutsch G, Philibert D. RU486. Sci Am 1990;262:42-8.

28. Bartley J, Brown A, Elton R, Baird DT. Doubleblind randomized trial of mifepristone in combination with vaginal gemeprost or misoprostol for induction of abortion up to 63 days gestation. Hum Reprod. 2001;16:2098-2102.

29. Knudsen UB. First trimester abortion with mifepristone and vaginal misoprostol. Contraception 2001;63:247-50.

30. Heikinheimo O, Lahteenmaki PL, Koivunen E, Shoupe D, Croxatto H, Luukkainen $\mathrm{T}$, et al. Metaboloism and serum binding of RU486 in women after various single doses. Hum Reprod. 1987;2:37985.

31. Creinin MD. Medical management of abortion. ACOG Practice Bulletin. 2001;26:1-3.

32. Carbonell JLL, Varela L, Velazco A, Fernandez C. The use of misoprostol for termination of early pregnancy. Contraception. 1997;55:165-8.

33. Roudsari FV, Ayati S, Saghafy N, Shaker M. Misoprostol alone or in combination with methotrexate for termination of pregnancy at first trimester. 2010;9:89-94.

34. Hoekstra M, Haagsma C, Neef C. Bioavailability of higher dose methotrexate comparing oral and subcutaneous administration in patients with rheumatoid arthritis. J Rheumatol. 2000;31:645-8.

Cite this article as: Bhaskar A, Kaushik R, Kumar A. A prospective comparative study of oral and vaginal misoprostol after pre-treatment with single dose of mifepristone for second trimester abortion. Int J Reprod Contracept Obstet Gynecol 2018;7:2726. 